\title{
Towards Modeling Rutting for Asphalt Pavements in Hot
}

\section{Climates}

\author{
Aaron Daniel Mwanza ${ }^{1}$, Mundia Muya ${ }^{2}$ and Peiwen $\mathrm{Hao}^{3}$ \\ 1. China Civil Engineering Construction Corporation, Fuzhou Research and Design Institute, Fuzhou 350013, China \\ 2. Department of Civil and Environmental Engineering, School of Engineering, University of Zambia, Lusaka 32379, Zambia \\ 3. Highway College, Chang'an University, Xi'an 710064, China
}

\begin{abstract}
Rutting is a chronic disease in asphalt pavements despite several mitigation measures. Although many attempts have been made by both researchers and practitioners to develop rutting prediction models, each model, however, has certain inherent limitations due to assumptions and data used during the development of the model. Placement of an asphalt overlay is the most common method used in Zambia to rehabilitate existing asphalt pavements. The objective of this research is to go towards developing a national rutting prediction model for use in tropical hot climates based on default finite element creep and elasto-visco-plastic analysis tools in ABAQUS. Dynamic modulus and repeated load tests are conducted on overlay mixtures designed based on the pavement residual structural adequacy from deflection tests to provide material properties for the constitutive rutting model. Unified, three dimensional linear viscoelastic boundary value problems were formulated for each five national representative pavement sections. In general, the FE (finite element) creep and elasto-visco-plastic rutting evolutions were in agreement with the measured laboratory scaled one third mobile load simulators. Performance ranking of the validated models revealed optimal pavement system combination suitable for calibration. The study recommends future directions for local adoption of the South African mechanistic-empirical design method currently being developed.
\end{abstract}

Key words: Finite element, rutting, creep, elasto-visco-plastic, overlay.

\section{Introduction}

The use of asphalt overlays is one of the most common methods used in Zambia to rehabilitate deteriorated existing asphalt pavement roads [1]. The type of an overlay and its required thicknesses are principally governed by the residual structural adequacy and strength of the existing PVMNT (pavement), determined mostly from non-destructive deflection tests such as the FWD (falling weight deflectometer). Once adequately constructed, the satisfactory performance of an asphalt overlay is influenced by various factors including the existing PVMNT conditions, traffic loading, and environmental conditions (temperature, etc.).

$\mathrm{PD}$ (permanent deformation) in asphalt overlays is

Corresponding author: Aaron Daniel Mwanza, Dr., Ph.D., research fields: rail-road pavement materials and design, APT and pavement modeling. most severe in hot climates particularly under heavy traffic loading [1]. Estimation and prediction of the maximum distresses likely to occur within the PVMNT layers after construction of an overlay is critical to optimize PVMNT design and management [2]. Constitutive modeling of the PD behavior of asphalt pavement structures enables PVMNT engineers to evaluate the PVMNT deterioration progress and develop regional specific performance based asphalt mix specifications [3].

In this study, FE (finite element) analysis tools in ABAQUS were used to simulate a PVMNT model structure based on user defined boundary conditions and PVMNT dimensions. Traffic loading, environmental factors and pavement material parameters (determined from laboratory tests) formed as input parameters to a mathematical formulation using the user defined subroutines in ABAQUS FE 
analysis whose output values were PDs. To validate the ABAQUS models and the related FE analysis, APT (accelerated pavement testing) with the MLS3 (third-scale mobile load simulator) was used to measure the PD on laboratory scaled constructed overlay test sections of the exact PVMNT structure and materials as the ABAQUS models.

\section{Study Objectives and Methodology}

Given the background above, the objectives of the work documented in this paper were three-fold, namely:

- To evaluate the PD models in ABAQUS platform for the suitability of predicting rutting in hot tropical climates like Zambia;

- To characterize the Zambian roads asphalt mixes for PD response and rutting performance;

- To determine the regional temperature correction factors that adequately account for the effect of prolonged heat and high temperatures on deflection measurements.

The study methodology incorporated NDT (nondestructive testing) with the FWD conducted on in-service roads for a period of 2 years in different seasons. Regional temperature correction factors are incorporated into the FWD raw data to determine the existing PVMT residual strength. In-situ characteristics of PVMNT layers in combination with dynamic modulus and repeated load testing on asphalt mixes provided material input parameters for the PD, FE analysis in ABAQUS. The PDs through $\mathrm{FE}$ analysis results in ABAQUS were compared to the rutting performance of various laboratory-scaled PVMNT structures under accelerated trafficking with the MLS3 as a step towards validating the Models 3 .

\section{Experimental Program}

As discussed in the subsequent text, the experimental design plan comprised of FWD testing, modulus back-calculation and computations, sensitivity analysis, asphalt mix design and laboratory testing, accelerated PVMNT testing with the MLS3 and ABAQUS FE modeling.

\subsection{FWD Testing}

Deflection response of a PVMNT to any applied load is an important indicator of the structural capacity, material property characterization, and subsequent PVMNT performance [4]. A Dynatest FWD model 8000 was used to collect deflection data, with typical test parameters, namely [5]: $40 \mathrm{kN}$ impulse load at one drop per point in the wheel path, $30 \mathrm{~cm}$ diameter circular foot plate, and seven geophones radially located at $0,203,306,457,610,914$, and $1534 \mathrm{~mm}$, interspacing [6]. Deflection measurements were taken at minimum $100 \mathrm{~m}$ inter-spacing on alternate lanes in the wheel path of two-lane roads located in several geographical locations of Zambia, with one lane in each direction.

In order to account for the effects of seasonal temperature variations on deflection measurements, FWD tests were conducted over a period of 2 years, spread over the three significant seasons of Zambia, namely rainy, cold, and hot season. Five representative PVMNT sections were selected and marked on each research section spread in different parts of the country. The sections were selected based on the variability in the visual condition survey with reference to road roughness, surface distress plus the in situ boring results for variations in the PVMNT cross-sectional layer thickness and material composition type. Laboratory tests were conducted on the asphalt mix overlays to determine engineering materials properties for each pavement overlay while the existing pavement layer's properties were determined by NDT. The thickness of each pavement layer were measured from field cores. The PVMT material properties, asphalt mix overlay properties and traffic loading formed as input parameters for a mathematical formulation using the user defined material sub routines for FE analysis to predict PD in the PVMT models. 
Table 1 Typical raw FWD test results.

\begin{tabular}{|c|c|c|c|c|c|c|c|c|c|c|c|c|c|}
\hline \multirow{3}{*}{$\begin{array}{l}\text { Typical } \\
\text { Chainage }(\mathrm{m}) \\
\text { and side of lane }\end{array}$} & \multicolumn{7}{|c|}{ Sensors and distance from the centre $(\mathrm{mm})$} & \multicolumn{2}{|c|}{ Loading } & \multicolumn{3}{|c|}{ Temperature $\left({ }^{\circ} \mathrm{C}\right)$} & \multirow{3}{*}{$\begin{array}{l}\text { Pulse } \\
\text { time (s) }\end{array}$} \\
\hline & D1 & $\mathrm{D} 2$ & D3 & D4 & D5 & D6 & D7 & \multirow{2}{*}{$\mathrm{kPa}$} & \multirow{2}{*}{$\mathrm{kN}$} & \multirow{2}{*}{ Air } & \multirow{2}{*}{ Sur } & \multirow{2}{*}{ Pave } & \\
\hline & $\overline{0}$ & 203 & 306 & 457 & 610 & 914 & 1,534 & & & & & & \\
\hline 7160 LHS & 399 & 213 & 136 & 49 & 29 & 21 & 17 & 566 & 40.01 & 29.5 & 31.6 & 39.9 & 31.36 \\
\hline 7200 RHS & 233 & 142 & 104 & 37 & 19 & 14 & 12 & 565 & 39.92 & 29.5 & 31.6 & 39.4 & 29.77 \\
\hline 7300 LHS & 200 & 135 & 107 & 46 & 25 & 16 & 12 & 565 & 39.94 & 30.9 & 32.3 & 42.8 & 30.96 \\
\hline 7400 RHS & 250 & 150 & 124 & 55 & 41 & 29 & 23 & 566 & 40 & 29.7 & 32.3 & 39.4 & 30.58 \\
\hline 7500 LHS & 248 & 121 & 70 & 27 & 20 & 15 & 13 & 573 & 40.51 & 31.4 & 32.3 & 42.8 & 31.41 \\
\hline Average & 266 & 152.2 & 108.2 & 42.8 & 26.8 & 19 & 15.4 & 567 & 40.1 & 30.2 & 32 & 40.9 & 30.8 \\
\hline Std. deviation & 77 & 35.6 & 25 & 11 & 8.9 & 6.2 & 4.7 & 3.4 & 0.2 & 0.9 & 0.4 & 1.8 & 0.7 \\
\hline Coef. of var. & 3.5 & 4.3 & 4.3 & 3.9 & 3 & 3.1 & 3.3 & 167.2 & 163.2 & 34 & 83.5 & 22.9 & 45.7 \\
\hline 90th percentile & 339.4 & 187.8 & 131.2 & 52.6 & 36.2 & 25.8 & 20.6 & 570.2 & 40.3 & 31.2 & 32.3 & 42.8 & 31.4 \\
\hline
\end{tabular}

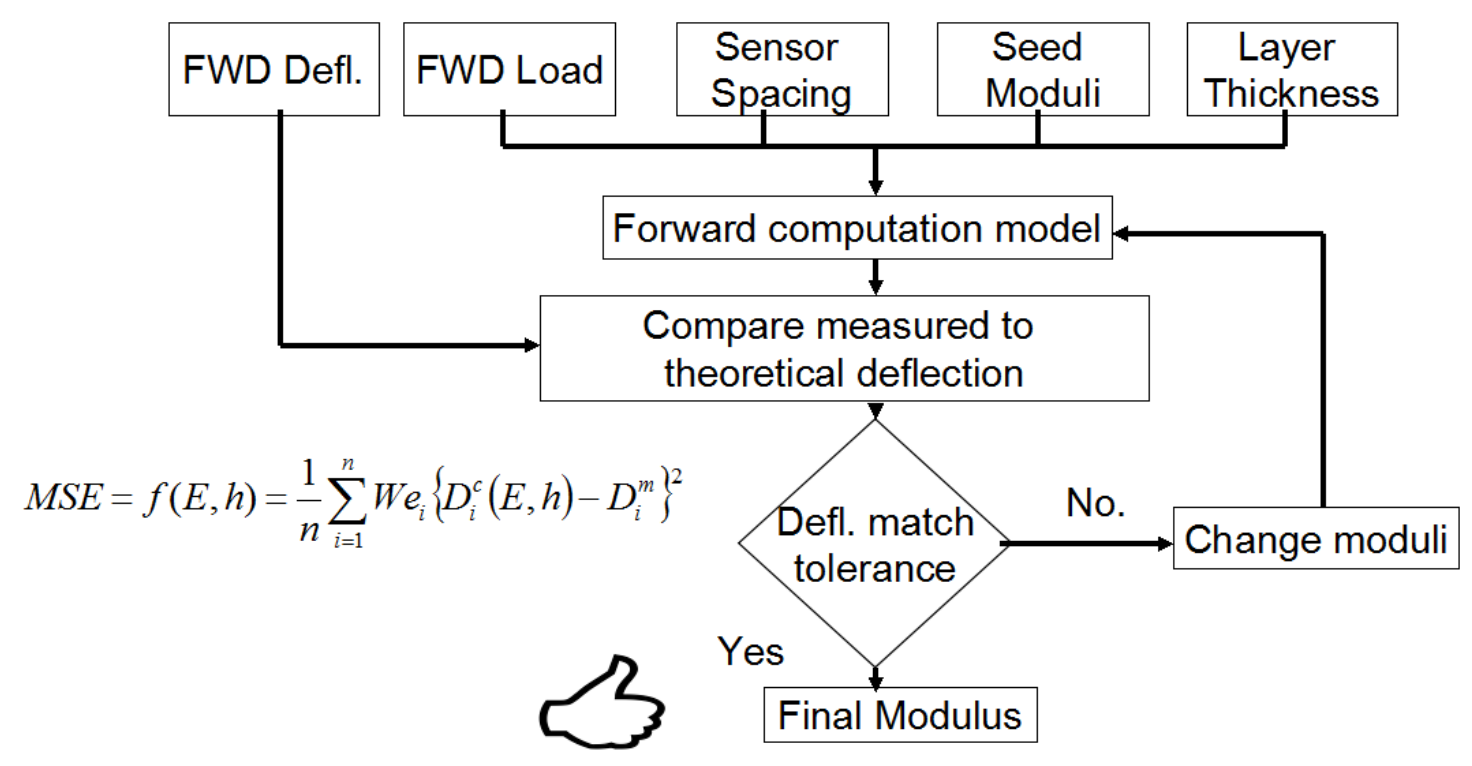

Fig. 1 Back calculations flow chart.

\subsubsection{Modulus Calculation-Back Analysis}

Based on the 90th percentile (Table 1), whose algorithm is shown in Fig. 1, a representative deflection basin was established for each PVMNT section for analyzing the representative moduli values.

Raw deflection measurements were normalized and calibrated for regional temperature correction through a protocol model that was developed by taking into account a 2-year seasonal temperature variation effects on deflection measurements before processing the elastic moduli back-calculations.

Back-calculation involves iterative and regression techniques to minimize errors between measured and calculated deflection values. This was computed using the following Eq. (1):

$$
M S E=f(E, h)=\frac{1}{n} \sum_{i=1}^{n} W e_{i}\left\{D_{i}^{c}(E, h)-D_{i}^{m}\right\}^{2}(1)
$$

where:

$$
D_{i}^{c}(E, h)=\text { calculated deflection at location } i
$$

based on $E$ and $h$, (mm);

$D_{i}^{m}=$ measured deflection at location $i,(\mathrm{~mm}) ;$

$n=$ number of FWD sensors,

$E=\left\{E_{1}, E_{2}, E_{3}, \ldots . ., E_{m}\right\}$ (unknown moduli of the layers, $\mathrm{MPa}$ );

$H=\left\{h_{1}, h_{2}, h_{3} \ldots \ldots h_{m-1}\right\}$ (known layer thickness);

$W e i=$ weighing factor for sensor $i(W e i=1$ if all sensors are given the same importance). 
$M S E=$ mean square error.

\subsubsection{Sensitivity Analysis of Modulus Values}

A temperature correction model that was developed in this study based on moduli obtained from back-calculation analysis of the evaluation of layer moduli (ELMOD) software at different temperatures was used to compare the moduli values obtained on each PVMT section throughout the temperature regime and season that the FWD tests were conducted. The default model format for temperature correction at $25{ }^{\circ} \mathrm{C}$ is expressed in Eq. (2) whose acceptable temperature range is $10^{\circ} \mathrm{C}$ to $60^{\circ} \mathrm{C}$ :

$$
D_{25}=D_{0} e^{0.279 T}
$$

where:

$D_{0}=$ measured center deflection ( $\left.\mathrm{mm}\right)$;

$T=25^{\circ} \mathrm{C}$ minus the temperature at the bottom of the wearing surface (approximately $40 \mathrm{~mm}$ from the surface), in ${ }^{\circ} \mathrm{C}$.

Say the pavement temperature at testing is $25{ }^{\circ} \mathrm{C}$, then the center deflection has a correction factor of 1 , at $35{ }^{\circ} \mathrm{C}$ then right hand side of equation 2 yields a correction factor of 0.6 .

In order to compare the deflections between sections, the deflection temperature models for each PVMNT section were normalized to the average HMA (hot mix asphalt) temperature during the testing period of $25^{\circ} \mathrm{C}$. An example of a generalized model for some PVMNT sections after nonlinear regression is shown in Fig. 2.

Raw (field) deflection results of the centre geophone at their corresponding seasonal test temperatures form a deflection bowl for the section of interest. The section deflection bowl which is an exponential function of test temperature is normalized/standardized for laboratory (Hamburg wheel) $25{ }^{\circ} \mathrm{C}$ deflection measurement resulting into Eq. (2). Temperature correction factors are established for each point deflection bowl (tested at different seasonal temperatures) by proportionality. Temperature correction factors can be read off from the relevant graph and applied to deflection measurements before in-putting into the Elmod back-calculation software [7]. Based on these adjustments, the corrected in-situ layer moduli were then utilized for development of $\mathrm{PD}$ and rutting prediction models. The residual life of each PVMNT section and the required overlay thickness were calculated based on the 1993 AASHTO (American Association of State Highway and Transportation Officials) PVMNT design guide. The 1993 AASHTO overlay thickness design method utilizes

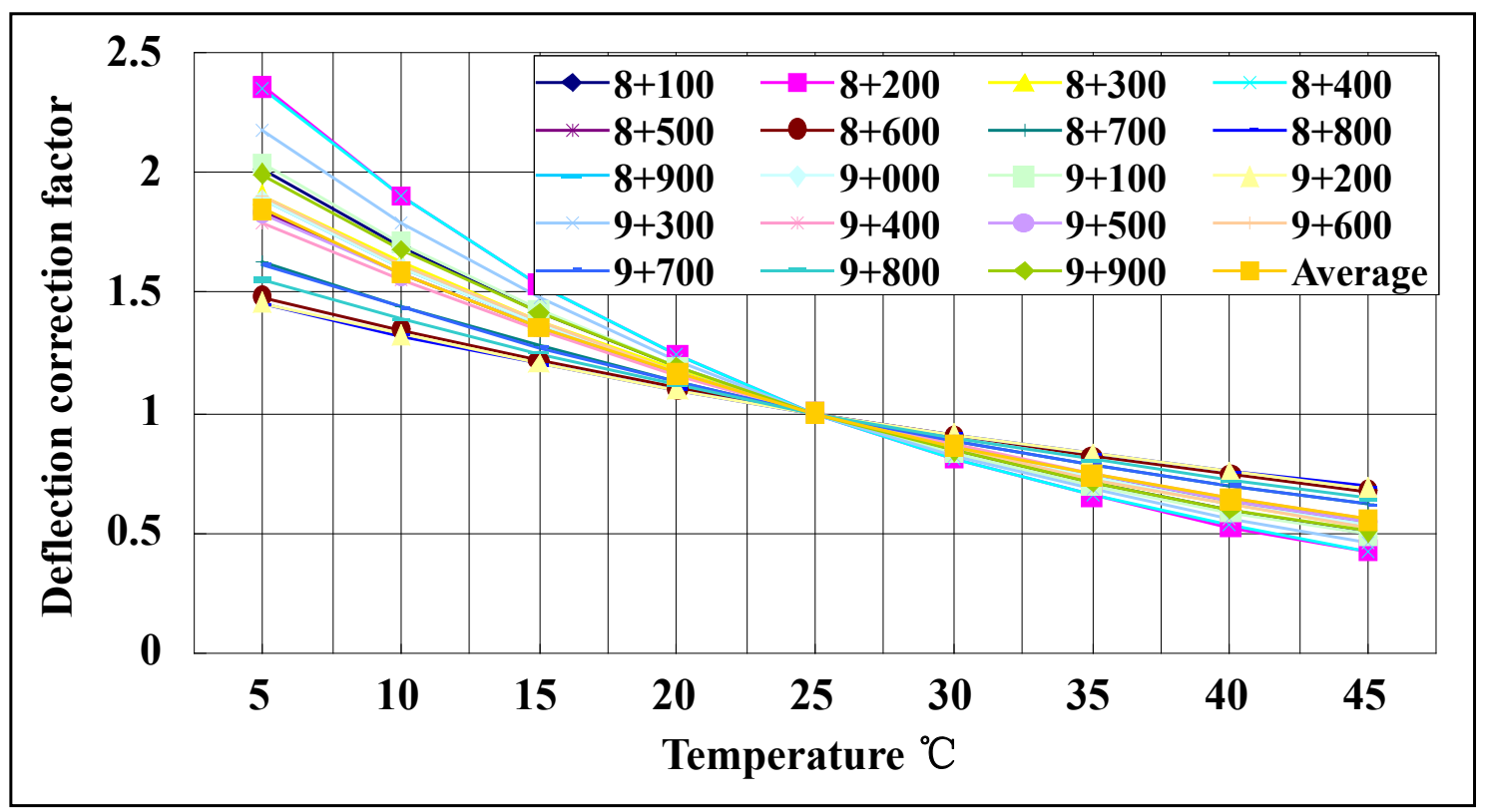

Fig. 2 Temperature correction factors $\left({ }^{\circ} \mathrm{C}\right)$ for deflection measurements. 
the effective thickness approach. The required thickness of the AC (asphalt concrete) overlay was determined and computed as a function of the structural capacity required to meet future traffic demands and the structural capacity of the existing pavement [8]:

$$
h_{O L}=\frac{S N_{O L}}{a_{O L}}=\frac{S N_{f}-S N_{e f f}}{a_{O L}}
$$

where:

$h_{O L}=$ required thickness of asphalt overlay (mm);

$S N_{O L}=$ required structural number of asphalt overlay;

$a_{O L}=$ structural layer coefficient of asphalt overlay;

$S N_{f}=$ structural number required to carry future traffic;

$S N_{\text {eff }}=$ total effective structural number of the existing pavement prior to overlay.

The design subgrade resilient modulus ( $M R$ value) was obtained from FWD measurements based on back-calculation analysis. The effective structural number $\left(S N_{\text {eff }}\right)$ was obtained using the AASHTO residual life method [8] and the results used in this research for structural numbers are shown below in Table 2.

\subsection{Asphalt Mix Design and Laboratory Testing}

The original and existing PVMNT structures were designed based on the South African standards and codes of practice [9]. Five asphalt mixes were prepared for use on each delineated PVMNT sections as seen in Table 1 and the SuperPave mix-design method was used to characterize the volumetric and engineering properties of the mixes. Laboratory tests on asphalt mixes that provided elastic- and viscoelastic-plastic properties included dynamic modulus $\left(\left|E^{*}\right|\right)$ [10], repeated load testing, $F N$ (flow number), and static creep - flow time (Ft) [11]. Dynamic modulus test was performed on the overlay mixes to obtain the modulus parameters for the surfacing course material that was used in the analysis for the models. For the creep model, dynamic and static creep compliance tests were performed to obtain the flow number and flow time respectively for determining creep model parameters $(A, n$, and $m)$. The frequency sweep at constant height test was performed to obtain the dynamic shear moduli $\left(G^{*}, G^{\prime}\right.$ and $\left.G^{\prime \prime}\right)$ and bulk moduli $\left(K^{*}, K^{\prime}, K^{\prime \prime}\right)$ as input parameters for the viscoelastic model.

Dynamic modulus for each mix was determined by conducting the test at two temperatures, thus $20^{\circ} \mathrm{C}$ and $35^{\circ} \mathrm{C}$ each at $0.1,0.5,1.5,10$, and $25 \mathrm{~Hz}$ frequencies, respectively and then generating $\left|E^{*}\right|$ master-curves at $35^{\circ} \mathrm{C}$ as a reference temperature that is representative of the Zambian summer high temperature regime when asphalt $\mathrm{PD}$ and rutting are more critical. The shift factors were determined using a sigmoidal function [12]. Eq. 4 shows the sigmoid function (master curve-fit equation) that was used in this study:

$$
\log \left|E^{*}\right|=\delta+\frac{\alpha}{1+e^{\beta-\gamma\left(\log \left(f_{r}\right)+S_{T}\right)}}
$$

$\left|E^{*}\right|=$ dynamic modulus;

$\delta=$ minimum modulus value;

$\delta+\alpha=$ maximum value of $\left|E^{*}\right|$;

$\beta$ and $\gamma=$ sigmoid function fitting parameters;

$f_{r}=$ reduced frequency at the reference temperature;

$S_{T}=$ shift factors.

The reduced frequency was computed using the equation below:

$$
\log f_{r}=\log f+\frac{\Delta E_{a}}{19.14714}\left(\frac{1}{T}-\frac{1}{T_{\gamma}}\right)
$$

where:

Table 2 Structural numbers for the research sections.

\begin{tabular}{llllll}
\hline \multirow{2}{*}{ Structural number } & \multicolumn{5}{c}{ Section } \\
\cline { 2 - 6 } & $\mathrm{A}$ & $\mathrm{B}$ & $\mathrm{C}$ & $\mathrm{D}$ & $\mathrm{E}$ \\
\hline$S N_{f}$ & 6.3 & 5.34 & 5.98 & 5.6 & 4.89 \\
$S N_{\text {eff }}$ & 5.76 & 4.85 & 5.37 & 4.56 & 3.80 \\
\hline
\end{tabular}


$f_{r}=$ reduced frequency at the reference temperature;

$f=$ loading frequency at the test temperature;

$T_{r}=$ reference temperature in ${ }^{\circ} \mathrm{K}$;

$T=$ test temperature in ${ }^{\circ} \mathrm{K}$;

$\Delta E_{a}=$ activation energy (treated as a fitting parameter).

The temperature shift factors are given by Eq. (6):

$$
\log a(T)=\log f+\frac{\Delta E_{a}}{19.14714}\left(\frac{1}{T}-\frac{1}{T_{\gamma}}\right)
$$

where:

$a(T)=$ shift factor at temperature $T$;

$T_{r}, T$ and $\Delta E_{a}=$ as defined in Eqs. (4) and (5).

\subsection{Accelerated Third-Scale Mobile Load Simulator} (MLS3) Testing

A model mobile load simulator MLS3 (MMLS3) is a one-third scale of a full scale APT machine with the potential to test the effect of different environmental impacts to rutting such as temperature under wet and dry conditions [13]. It can be applied both in the laboratory and in the field. The MMLS3 consists of four axles, each with a $300 \mathrm{~mm}$ diameter inflated pneumatic wheel, circulating in a vertical closed loop. The nominal wheel speed is $2.5 \mathrm{~m} / \mathrm{s}$ resulting in 7,200 wheel loadings per hour. Slower speeds can be selected if desired. A series of accelerated load testing on laboratory scaled pavement sections as shown in Fig. 3 were carried out and rut depth was recorded at profile meter gauge positions of every 1,000 incremental load applications under a one-third scaled value of the actual truck wheel. The tyre pressure was set at $750 \mathrm{kPa}$ at a wheel load of 2.9 $\mathrm{kN}$ and temperature of $25{ }^{\circ} \mathrm{C}$ in conformity with the average HMA test temperature during the period of conducting the deflection tests on in service pavements. Basic asphalt mix material properties are shown in Table 3.

Table 3 Basic material characteristics for the asphalt mixes.

\begin{tabular}{|c|c|c|c|c|}
\hline PVMNT section & $\mathrm{A}$ & $\mathrm{B}$ & $\mathrm{C}$ & $\mathrm{D}$ and $\mathrm{E}$ \\
\hline Chainages $(\mathrm{km})$ & $7.16 \sim 7.5$ & $9.9 \sim 13.8$ & $16.8 \sim 18.75$ & $\begin{array}{l}21.8 \sim 24.2 \mathrm{D} \\
36.7 \sim 38.5 \mathrm{E}\end{array}$ \\
\hline Binder type & $60 / 70$ & PG64-22 & PG70-22 & PG58-40 \\
\hline Filler additive & Limestone & Portland cement & Hydrated lime & Limestone \\
\hline Sample type & Core & Loose mix & Loose mix & Loose mix \\
\hline Polymer modified & No & No & Yes & Yes \\
\hline Paving date & May-09 & May-09 & Jun-09 & Jun-09 \\
\hline Nominal aggregates size $(\mathrm{mm})$ & 19.0 & 12.5 & 12.5 & 12.5 \\
\hline$N_{\text {design }}$ (design number of gyrations) & 100 & 75 & 100 & 100 \\
\hline \multicolumn{5}{|l|}{ AS - constructed volumetric properties } \\
\hline$A C(\%)$ - asphalt content & 5.61 & 5.2 & 5.3 & 5.4 \\
\hline $\begin{array}{l}A V @ N_{\text {design }}(\%) \text { - air voids at design } \\
\text { number of gyrations }\end{array}$ & 4.08 & 3.33 & 4.4 & 4.4 \\
\hline$V M A$-voids in mineral aggregate & 18.4 & 15.8 & 18.862 & 17.4 \\
\hline$V F A$ - voids filled with air & 55.2 & 59.1 & 51.8 & 57.1 \\
\hline$\% \mathrm{G}_{\mathrm{mm}} @ \mathrm{~N}_{\mathrm{ini}}$ & 88.2 & 88.8 & 85.4 & 85.5 \\
\hline$\% \mathrm{G}_{\mathrm{mm}} @ \mathrm{~N}_{\mathrm{des}}$ & 96.1 & 95.6 & & \\
\hline$\% \mathrm{G}_{\mathrm{mm}} @ \mathrm{~N}_{\max }$ & 97.2 & 99.9 & 97.2 & 97.3 \\
\hline In-situ $A V(\%)$ & $6.00 \pm 0.5$ & $6.75 \pm 0.5$ & $9.38 \pm 0.5$ & $7.00 \pm 0.5$ \\
\hline
\end{tabular}

Note: Though SuperPave design protocols were used in Section A, the binder is Pen-Grade selected as the country predominantly uses pen grade. $\% \mathrm{G}_{\mathrm{mm}} @ \mathrm{~N}_{\mathrm{ini}}$ (percent of maximum specific gravity of paving mixtures) at the initial number of gyration, $\% \mathrm{G}_{\mathrm{mm}} @ \mathrm{~N}_{\mathrm{des}}$ (percent of maximum specific gravity of paving mixtures at the design number of gyrations), $\% \mathrm{G}_{\mathrm{mm}} @ \mathrm{~N}_{\max }$ (percent of maximum specific gravity of paving mixtures at the maximum number of gyrations). 


\section{FE Problem and Mathematical Model Formulation}

Three models in ABAQUS Version 6.10 were selected: namely, creep, elasto-visco-plastic, and viscoelastic. The model selection criteria were based on the ability to conduct material characterization tests for the required input data [15]. The PVMT configuration and boundary conditions adapted are shown in Fig. 4. Representative PVMNT sections and basic material characteristics required for Superpave mixes [14] are shown in Table 3.and the parameters used in each FE non-linear dynamic analysis are shown in Table 4.

\section{Results, Analysis and Discussions}

PD prediction models implementation in ABAQUS showed that the viscoelastic model could not capture the PD response characteristics [16]. The displacements measured were too small $(2 * \mathrm{E}-11 \mathrm{~mm})$ in magnitude,
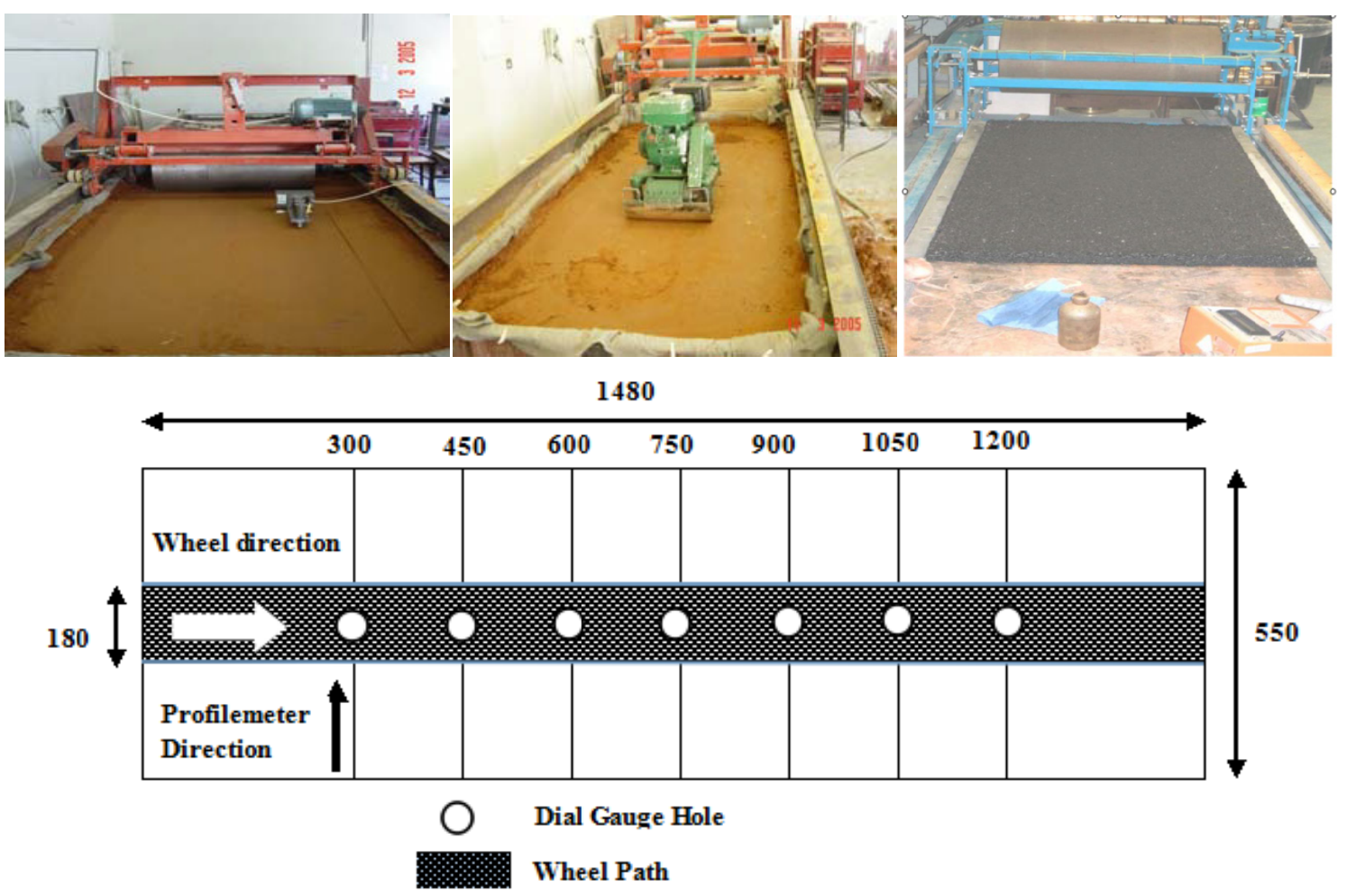

All dimensions in $\mathbf{m m}$

Fig. 3 Schematic of PVMNT test preparation and profile marking.

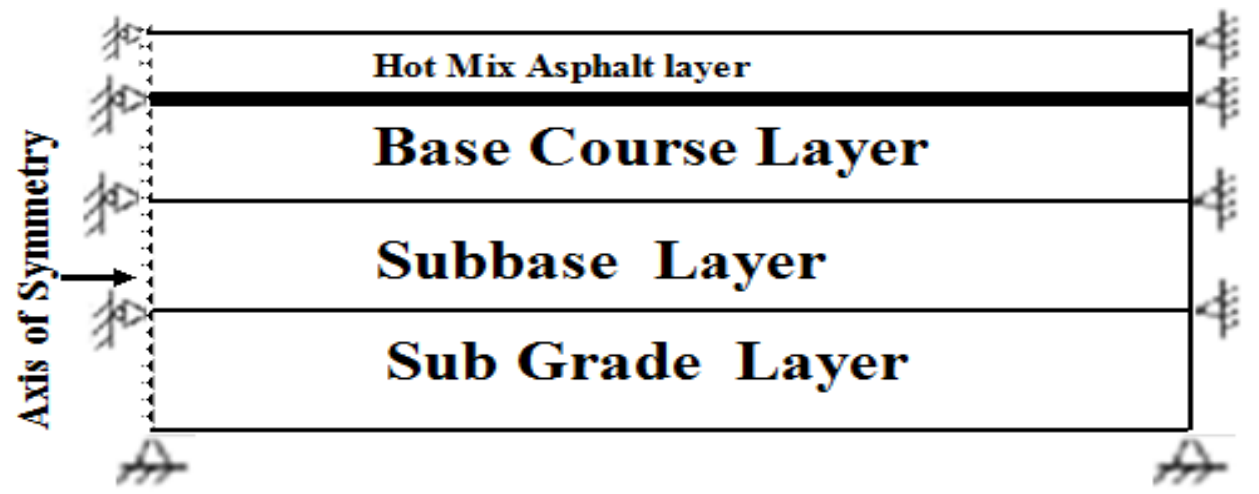

Fig. 4 PVMNT configuration and boundary conditions for ABAQUS analysis. 
Table 4 Finite element model and PVMT sections parameters.

\begin{tabular}{|c|c|c|c|c|c|c|}
\hline \multirow{2}{*}{\multicolumn{2}{|c|}{\begin{tabular}{|l|} 
Overlay mix type \\
Section chainages $(\mathrm{km})$ \\
\end{tabular}}} & A & B & $\mathrm{C}$ & $\mathrm{D}$ & $\mathrm{E}$ \\
\hline & & $7.16 \sim 7.5$ & $9.9 \sim 13.5$ & $16.8 \sim 18.7$ & $21.8 \sim 24.2$ & $36.7 \sim 38.5$ \\
\hline \multirow{6}{*}{ 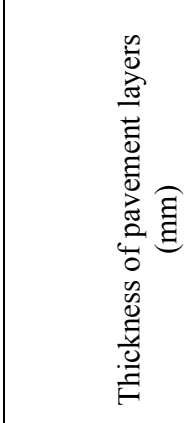 } & $100 \mathrm{~mm}$ & 65 & 55 & 80 & 80 & 80 \\
\hline & $200 \mathrm{~mm}$ & \multirow{3}{*}{180} & \multirow{2}{*}{185} & & \multirow{2}{*}{165} & \multirow{3}{*}{165} \\
\hline & & & & 175 & & \\
\hline & $300 \mathrm{~mm}$ & & \multirow{3}{*}{230} & & \multirow{3}{*}{210} & \\
\hline & $400 \mathrm{~mm}$ & 190 & & \multirow{3}{*}{230} & & \multirow{2}{*}{210} \\
\hline & $500 \mathrm{~mm}$ & & & & & \\
\hline & & & & & & \\
\hline
\end{tabular}

Material models parameters from experimental tests conducted at $35{ }^{\circ} \mathrm{C}$ reference temperature

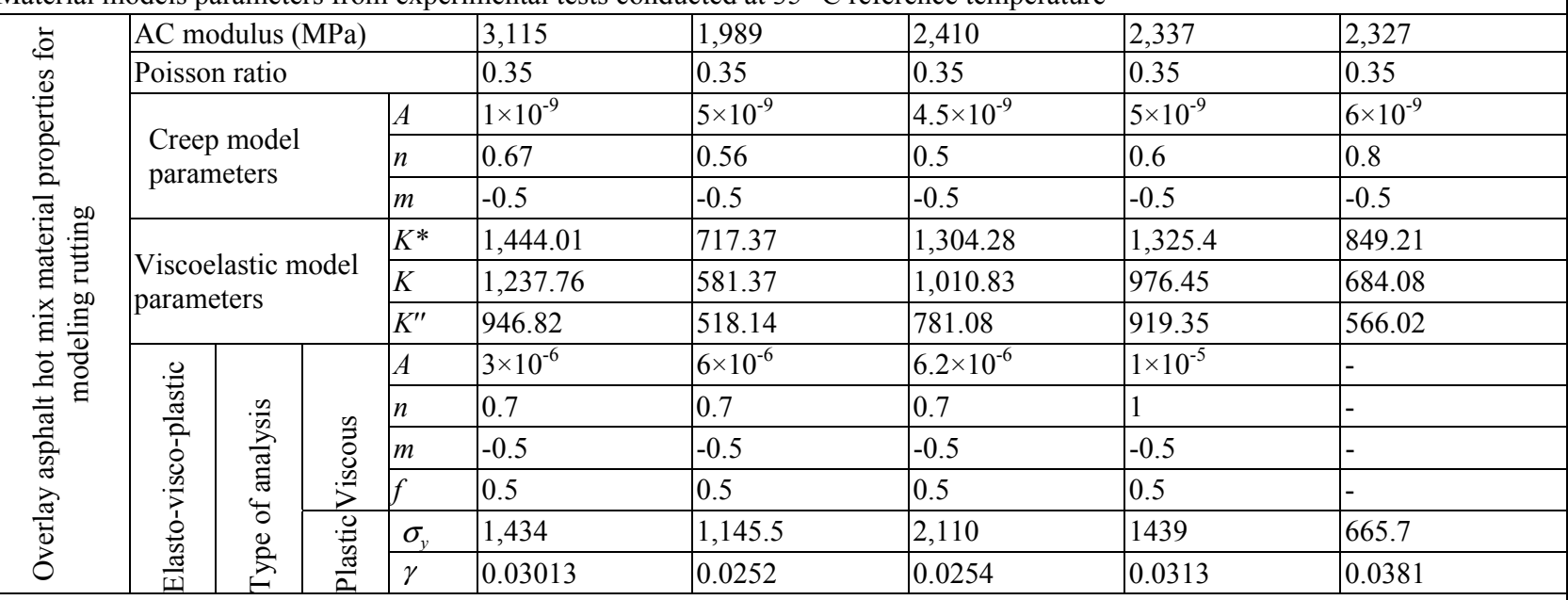

FWD test results conducted at $25^{\circ} \mathrm{C}$ average HMA temperature

\begin{tabular}{|c|c|c|c|c|c|c|}
\hline \multirow{2}{*}{ Base layer } & Elastic modulus (MPa) & 1241 & 1250 & 1613 & 1127 & 1127 \\
\hline & Poisson ratio & 0.45 & 0.45 & 0.45 & 0.45 & 0.45 \\
\hline \multirow{2}{*}{ Subbase layer } & Elastic modulus (MPa) & 305 & 542 & 331 & 200 & 220 \\
\hline & Poisson ratio & 0.45 & 0.45 & 0.45 & 0.45 & 0.45 \\
\hline \multirow{2}{*}{ Subgrade layer } & Elastic modulus (MPa) & 257 & 309 & 292 & 157 & 180 \\
\hline & Poisson ratio & 0.45 & 0.45 & 0.45 & 0.45 & 0.45 \\
\hline \multirow{5}{*}{\multicolumn{3}{|c|}{ Legend on type of under laying layers }} & \multicolumn{4}{|c|}{ Hot mix asphalt (overlay) on capping layer (white color) } \\
\hline & & & \multicolumn{4}{|c|}{ Crushed stone base/dense macadam } \\
\hline & & & \multicolumn{4}{|c|}{ Cement stabilized gravel } \\
\hline & & & \multicolumn{4}{|c|}{ Unbound gravel fill } \\
\hline & & & \multicolumn{4}{|c|}{ Selected fill on in-situ subgrade (black shows interface with subba) } \\
\hline
\end{tabular}

Table 5 FE model and MLS3 results with mix ranking.

\begin{tabular}{|c|c|c|c|c|c|c|c|c|}
\hline \multicolumn{4}{|c|}{ Elasto-visco-plastic model } & \multirow{2}{*}{$\begin{array}{l}\text { MLS3 } \\
(\mathrm{mm})\end{array}$} & \multicolumn{4}{|c|}{ Creep model } \\
\hline $\begin{array}{l}\text { Mix/ } \\
\text { PVMT ID }\end{array}$ & $\begin{array}{l}\text { Load repetitions } \\
\times 1,000\end{array}$ & $\begin{array}{l}\text { Permanent } \\
\text { deformation }(\mathrm{mm})\end{array}$ & Rank & & $\begin{array}{l}\text { Mix/ } \\
\text { PVMT ID }\end{array}$ & $\begin{array}{l}\text { Load repetitions } \\
\times 1,000\end{array}$ & $\begin{array}{l}\text { Permanent } \\
\text { deformation }(\mathrm{mm})\end{array}$ & Rank \\
\hline A & 300 & 6.23 & 3 & 7.18 & A & 300 & 6.84 & 4 \\
\hline B & 300 & 5.54 & 2 & 6.02 & $\mathrm{~B}$ & 300 & 5.79 & 2 \\
\hline C & 300 & 3.49 & 1 & 4.45 & $\mathrm{C}$ & 300 & 2.81 & 1 \\
\hline $\mathrm{D}$ & 300 & 7.32 & 4 & 8.50 & $\mathrm{D}$ & 300 & 6.17 & 3 \\
\hline E & 300 & 10.1 & 5 & 14.0 & E & 300 & 12.3 & 5 \\
\hline
\end{tabular}

Note: MLS3 (one third mobile load simulator) load repetitions by step load increment to the required future traffic volume (ESAL (equivalent standard axles)) was applied for non linear dynamic load FE analysis.MLS3 attained the same ESAL for total PD comparison measured from the surface or top-down. 
which can be considered negligible [17]. Two models, the creep and elasto-visco-plastic, were able to capture the PD response characteristics of the asphalt (AC) mixes [18]. A linear formulation was subsequently used to predict the evolution of PD in the asphalt mixes. Performance ranking of the models for each asphalt mix can be used to characterize and develop specifications for SuperPave mixes [19].

It can be seen from Table 5 that the two model predictions are very close to each other due to the complementary creep compliance found in both PD models [20]. The APT prediction from the MLS3 is also comparable to the analytical model PD predictions, albeit that its PD values are about 5\% higher than the analytical PD values. Overall, the results from laboratory testing, field FWD testing, APT, and numerical modeling were plausible and substantiated the significance of local temperature normalization of the FWD deflection measurements.

\section{Conclusions}

In-situ material tests were conducted using NDT techniques (i.e., FWD) to design overlay mixes. Laboratory tests were performed on the overlay mixes to generate model input parameters needed for FE ABAQUS analysis. In order to validate the models, APT trafficking with the MLS3 was performed on the scaled laboratory constructed PVMNT sections to further compare the PD performance of the five overlay (AC) mixes. From the results and study findings, the following conclusions were drawn:

- The two models, creep and elasto-visco-plastic, predicted a total PD that is close to the APT (MLS3) measured values; hence, the models are considered reliable with modifications through sensitivity analysis as suggested in this paper;

- The FWD tests provided reliable information for the PVMNT layer moduli values that can be used for $\mathrm{PD}$ analysis in ABAQUS;

- It has been demonstrated that back-calculation techniques in ELMOD software need temperature correction factors that are project specific to achieve reliable and representative $\mathrm{PD}$ predictions;

- Asphalt mixes were ranked for their PD and rutting performance; therefore, calibration of the rutting models can be carried out based on APT in the field or lab as well as observation of rutting performance in service.

\section{References}

[1] Zambia Roads. 1999. A Guide to the Design of Road Pavements. Final draft. A Roads Department publication. Lusaka: Zambia Roads.

[2] Huang, Y. H. 2004. Pavement Analysis and Design. 2nd ed. Upper Saddle River: Pearson Prentice Hall.

[3] Choubane, B., and McNamara, R. L. 2000. A Practical Approach to Predicting Subgrade Moduli Using Falling Weight Deflectometer (FWD) Data. Florida Dept. of Transportation.

[4] Appea, A. K. 2003. "Validation of FWD Testing Results at the Virginia Smart Road: Theoretically and by Instrument Responses." Ph.D. dissertation, Virginia Polytechnic Institute and State University.

[5] Mwanza, A. D. 2013. "Modeling of Rutting Prediction for Flexible Pavements in Zambia." Ph.D. dissertation, Chang'an University.

[6] Ullidtz, P., and Coetzee, N. F. 1995. "Analytical Procedures in Nondestructive Testing Pavement Evaluation and ELMOD 5 Procedures." Transportation Research Record 1482: 32-56.

[7] Wu, Z., Chen, X., Garspard, K., and Zhang, Z. 2008. "Structural Overlay Design of Flexible Pavement by Nondestructive Test Methods in Louisiana." In Proceedings of 87th Transportation Research Board Annual Meeting, 7-9.

[8] AASHTO (American Association of State Highway and Transportation Officials). 1993. AASHTO Guide for Design of Pavement Structures. Washington, D.C.: AASHTO.

[9] SSATCC (Southern Africa Transport and Communications Commission). 1998. Draft Code of Practice for the Design of Road Pavements. Pretoria: SATCC.

[10] American Association of State Highway and Transportation Officials AASHTO:TP62-03. 2003. Standard Method of Test for Determining Dynamic Modulus of Hot-Mix Asphalt Concrete Mixtures. Washington D.C.: AASHTO.

[11] American Association of State Highway and 
Transportation Officials AASHTO T320-03. 2007. Standard Method of Test for Determining the Permanent Shear Strain and Stiffness of Asphalt Mixtures Using the Superpave Shear Tester (SST). Washington D.C.: AASHTO.

[12] Pellinen, T. K., Witczak, M. W., and Bonaquist, R. F. 2004. "Asphalt Mix Master Curve Construction Using Sigmoidal Fitting Function with Non-linear Optimization." American Society of Civil Engineers, Reston, VA 20191-4400.

[13] Wang, Y., Grundling, J., and Steynberg, L. 2011. "Accelerating Pavement Testing for Temperature Changes and Sustainability by Model Mobile Load Simulator (MMLS) in South Africa." In Proceedings of The 16th Hong Kong Society for Transportation Studies (HKSTS) International Conference, 557-64.

[14] Asphalt Institute. 2001. Superpave Mix Design. Superpave Series No. 2 (SP-2). Asphalt Institute.

[15] Goh, S. W. 2009. "Development of Specifications for the Superpave Simple Performance Test." Master thesis,
Michigan Technological University.

[16] Theyse, H. L., De Beer, M., and Rust, F. C. 1996. "Overview of South African Mechanistic Pavement Design Method." Transportation Research Record 1539: 6-17.

[17] Park, D. W. 1996. "Characterization of Permanent Deformation in Asphalt Concrete Using a Laboratory Prediction Method and an Elastic Visco Plastic Model." Ph.D. dissertation, Texas A\&M University.

[18] Witczak, M. W., Kaloush, K., El-Basyouny, M., and Quintus, H. V. 2002. Simple Performance Test for Superpave Mix Design. NCHRP report 465.

[19] Epps, A., Walubita, L. F., and Bangera, N. U. 2003. "Pavement Response and Rutting for Full-Scale and Scaled APT." Journal of Transportation Engineering 129 (4): 451-61.

[20] Erkens, S. M. J. G., Liu, X., and Scarpas, A. 2002. “3D Finite Element Model for Asphalt Concrete Response Simulation." International Journal of Geomechanics 2 (3): 305-30. 